\title{
Survival of lactic acid bacteria in sea water. A factorial study
}

\author{
J. A. Vázquez, M.L. Cabo, M.P. González \& M.A. Murado \\ Instituto de Investigations Mariñas (CSIC). \\ r/ Eduardo Cabello, 6. Vigo-36208. Galicia - Spain
}

Key words: Survival kinetics, lactic acid bacteria, factorial design.

\begin{abstract}
A feasibility study of lactic bacteria as potential probiotics in larval cultures of marine fish was performed by investigating the survival of five strains of lactic bacteria in sea water by readily standardised procedures at different temperatures and salinities. These conditions were chosen in such a way that their combinations define a complete first order factorial design. Depending on the strain and the ambient conditions, the survival adhered to first order kinetics in some cases and to the Gompertz equation in others. The half lives $\left(t_{0.5}\right)$ calculated from these models were subsequently introduced as responses to the factorial designs, estimating the coefficients of empirical equations which describe the group effect of temperature and salinity on $t_{0.5}$. Simply additive effects were found in two cases, a negative first order interaction in another case, whilst another two required second order models.
\end{abstract}

\section{Introduction}

One of the most serious problems regarding the culture of marine fish, in particular turbot (Scophthalmus maximus), relates to the high mortality in the critical phases of larval development [1]. This mortality is associated with opportunistic bacteria [2, 3] which readily 
develop when live food and microalgae are used [4, 5]. Moreover, in the 3-5 days following exogenous larval feeding, strong decreases in ingestion due to bacterial surplus are frequent, leading to a total rejection of food and massive mortalities. Application of antibiotics significantly improves survival [6], but weakens the intestinal flora and induces the selection of resistant micro-organisms with unpredictable long-term effects to the environment and human health.

Probiotics are a promising alternative to antibiotics, i.e., food supplements consisting of live micro-organisms with beneficial effects to the host organism by improvement of the intestinal microbial balance [7]. Probiotic effects have been related to increases in disease resistance by stimulation of natural defences or immune responses; competition with pathogenic micro-organisms for limiting nutrients or adhesion points to the mucous; and the production of inhibitory substances. Despite the fact that the evidence for these effects remains inconclusive, in the most clearest cases it has been shown that (1) the microorganisms involved are usually lactic bacteria such as Lactococcus, Lactobacillus, Bifidobacillus [8], Leuconostoc or Pediococcus, (2) the probiotic activity is often conserved in the cell-free medium of the probiont cultures, which alludes to the role of specific metabolites, such as anti-microbial peptides produced by the lactic bacteria (bacteriocins).

Reproducible and quantitative work with probiotics and their possible application to other micro-organisms requires an understanding of the survival of potential probiotics in the marine medium. However, in spite of studies regarding survival in sea water of bacterial indicators of environmental quality, such as faecal [9, 10] or, specifically, Escherichia coli $[11,12,13]$, there are no data of this type for lactic bacteria (LAB). 
In this work the survival curves of different species of LAB in sea water are determined. The effects of salinity, temperature and their interactions on bacterial half-lives are studied by readily standardised procedures to evaluate feasibility as probiotics for turbot larval cultures.

\section{Materials and Methods}

Microbiological methods

The micro-organisms used included Lactococcus lactis CECT 539 (abbreviated key Lc 1.04), Lactobacillus brevis CECT 216 (Lb 2.01), Lactobacillus casei ssp. casei CECT 4040 (Lb 3.03), Lactobacillus casei ssp. casei CECT 4043 (Lb 3.04), and Pediococcus acidilactici NRRL B-5627 (Pc 1.02). Stock cultures were stored at $-50^{\circ} \mathrm{C}$ in powdered skimmed milk suspension with 25\% glycerol [14]. Micro-organisms were grown in $300 \mathrm{ml}$ Erlenmeyer flasks with $100 \mathrm{ml}$ of MRS medium (DIFCO) at $30^{\circ} \mathrm{C}$ with $200 \mathrm{rpm}$ orbital shaking. Inocula $(0.5 \% \mathrm{vol} / \mathrm{vol})$ consisted of cellular suspensions from $20 \mathrm{~h}$ aged cultures on the same medium and under the same conditions, adjusted to an OD (700 nm) of 0.900 .

For the survival tests the biomass of $10 \mathrm{~h}$ cultures were used, collected by centrifugation at $10,000 \mathrm{~g}$ for $10 \mathrm{~min}$. From a previous calibration of the relationship between dry weight and optic density at $700 \mathrm{~nm}$ the sediments were resuspended in $0.9 \% \mathrm{KCl}$ and the suspensions used $(<0.5 \% \mathrm{vol} / \mathrm{vol})$ to supply initial populations of $1 \mathrm{~g} \mathrm{l}^{-1}$ to the experimental units. These units consisted of $300 \mathrm{ml}$ Erlenmeyer flasks with $100 \mathrm{ml}$ of sea water of various salinities maintained in orbital stirring (200 rpm) at different temperatures (Table 1). 
At predetermined times, viable cells were quantified by means of a plate count technique on MRS agar. Serial 10-fold dilutions were prepared in peptone buffered solutions and $0.1 \mathrm{ml}$ samples were plated in quadruplicate, incubated at $30^{\circ} \mathrm{C}$ overnight and manually counted. Results were expressed in colony forming units per $\mathrm{ml}\left(\mathrm{CFU} \mathrm{ml}{ }^{-1}\right)$. In tests involving starvation, the counting is usually performed in dilute media, although here this precaution can be ignored here. Accordingly, the results obtained represent the most severe operating conditions.

Experimental design and statistics

The experimental plan was organised to permit two approximations. Firstly, the temporal variation of the population was adjusted to adequate functional forms for determining the half-life of the micro-organisms. Secondly, the combinations of salinity and temperature were chosen to define a complete first order orthogonal design [15] in which half-lives can be introduced as responses. In the first case, the calculation was carried out by means of a non-linear least squares test (quasi-Newton). Results of the factorial designs (orthogonal least-squares calculation) were used to obtain empirical equations which describe half-lives as a function of temperature and salinity. Statistical significance of the coefficients was verified by means of the student t-test $(\alpha=0.05)$, and model consistency by means of the Fisher $\mathrm{F}$ test $(\alpha=0.05)$ applied to following means squares ratios:

Model / Total error

(Model + Lack of fitting) / Model

Total error / Experimental error

Lack of fitting / Experimental error. 


\section{Results and Discussion}

Survival kinetic analysis

To describe the kinetics of survival the experimental data were normalised (the number of $\mathrm{cfu} / \mathrm{ml}$ corresponding to the initial load of $1 \mathrm{~g} \mathrm{l}^{-1}$ ) and adjusted to two equations from which the times necessary for the population to be reduced to $50 \%\left(t_{0.5}\right.$ or half life, parameter affected by the minimal error) and $10 \%$ of the initial ( $t_{0.1}$ which may be a more intuitive vision of survival) were deduced.

The first of the equations corresponded to a first order decay process:

$$
\frac{d N}{d t}=-\mu N
$$

which, resolved for initial conditions $t=0$ and $N=N_{0}$, produces the explicit form:

$$
N=N_{0} \exp (-\mu t) \text {, where: }
$$

$N$ : number (normalized) of CFU, with $N_{0}$ as initial value $\mu$ : specific mortality (dimensions $t^{-1}$ )

and where $t_{0.5}$ and $t_{0.1}$ values can be obtained by replacing in (2) $N$ by $N_{0} / 2$ and $N_{0} / 10$ :

$$
\begin{aligned}
& \frac{N_{0}}{2}=N_{0} \exp \left(-\mu t_{0.5}\right) ; t_{0.5}=\frac{\ln (2)}{\mu} \\
& \frac{N_{0}}{10}=N_{0} \exp \left(-\mu t_{0.1}\right) ; t_{0.1}=\frac{\ln (10)}{\mu}
\end{aligned}
$$


The second equation applied was that of Gompertz (1825):

$$
\frac{d N}{d t}=c N(\ln a-\ln N)
$$

which, similarly resolved for initial conditions $t=0$ and $N=N_{0}$ :

$$
N=a \exp [-b \exp (c t)] \text {, where: }
$$

$$
\begin{aligned}
& N \text { : number (normalized) of CFU } \\
& a \text { : fitting parameter (dimensions: } N \text { ) } \\
& b \text { : fitting parameter (dimensionless), related with } N_{0} \text { through: } b=\ln \left(a / N_{o}\right) \\
& \left.c \text { : fitting parameter (dimensions: } t^{-1}\right)
\end{aligned}
$$

The constants $t_{0.5}$ and $t_{0.1}$ are obtained as in the preceding case, but adjusting $N_{0} / 2$ and $N_{0} / 10$ to the limit of the function when time tends to zero:

$$
\begin{aligned}
& N_{0}=\lim _{t \rightarrow 0} N=\lim _{t \rightarrow 0} a e^{-b e^{0}}=a e^{-b} ; \text { then: } \\
& N=\frac{N_{0}}{2}=\frac{a e^{-b}}{2} ; \frac{a e^{-b}}{2}=a e^{-b e^{C t_{0,5}}} ; \text { and, finally: } t_{0.5}=\frac{1}{C} \ln \left[1+\frac{\ln 2}{b}\right] \\
& \text { Similarly, when } N=N_{0} / 10: t_{0.1}=\frac{1}{C} \ln \left[1+\frac{\ln 10}{b}\right]
\end{aligned}
$$

The fits of the experimental series to these two equations are shown in Figures 1 to 2 (Pc 1.02 and Lb 3.04 like example), and the corresponding values of $t_{0.5}$ and $t_{0.1}$ are shown in Table 2. It is clear that the most adequate model for describing the results depends on the 
strain and test conditions, with no other meaning than that directly obtained from the curves. For certain species or conditions mortality can be assimilated to a first order kinetic process, similar to sterilisation at high temperatures $[17,18]$. In other cases, however, the decrease of the bacterial population demonstrates an initial period of reduced mortality and suggests resistance mechanisms. In these cases the survival profile is better adjusted to the equation of Gompertz and is readily paralleled to those found from sterilisation by gentle thermal process $[19,20,21,22,23]$.

\section{Temperature-salinity interactions}

Introducing the half lives as responses $(Y)$, the temperature $(T)$ and salinity $(S)$ combinations which define the orthogonal design specified in Table 1 were determined (see Methods), and fitting each group to a model of the type:

$$
Y=b_{0}+b_{1} S+b_{2} T+b_{12} S T
$$

For the species Lb 3.04, Lc 1.04 and Pc 1.02 all the significant criteria specified above validated the half-life descriptions as a function of $T$ and $S$ with equation (7) with the coefficients given in Table 3 (Table 4 shows, for example, the statistical analyses corresponding to Lb 3.04). In the other two species tested (Lb 2.01 and Lb 3.03) the Fisher test applied to the relationship between experimental error and lack of model fitting demonstrated that the functional form (7) was not adequate for the description of the results. In addition, the distribution of the deviations suggested the need for second order terms. In routine applications, it is advisable to change the orthogonal for the rotatable design for deriving quantitative empirical models in these cases of complex response [15]. 
The response surfaces corresponding to the three first order cases are shown in Figure 3. Survival increases with temperature and decreases with salinity. In addition, within the experimental domain both effects are simply additive in Lc 1.04 and Pc 1.02, whereas in Lb 3.04 a negative interaction (shortening of the half-life) is demonstrated.

\section{ACKNOWLEDGEMENTS}

To Xunta de Galicia for its financial support (Project PGIDT99MAR40203), and to Dr.

Lorenzo Pastrana for their technical assistance. José Antonio Vázquez Álvarez was a doctoral fellow of CSIC-Deputación de Pontevedra.

\section{Literature cited}

1. Person-Le Ruyet J (1989) The hatchery rearing of turbot larvae (Scophthalmus maximus). Cadernos da Área de Ciencias Mariñas. Seminario sobre Tecnoloxía do Cultivo do Rodaballo 3:56-92

2. Muroga K, Higashi M, Keitoku H, (1987) The isolation of intestinal microflora of farmed red sea bream (Pagrus major) and black seabream (Acanthogagrus schlegeli) at larval and juvenile stages. Aquaculture 65:79-88

3. Munro P, Birkbeck TH, Barbour A (1994) Comparison of the gut bacterial flora of start-feeding larval turbot readed under different conditions. J Appl Bacteriol 77:560-566

4. Lesel R (1981) Microflore bacteriénne du tractus digestif. In Nuttrition des poissons París: Ed. CNRS, 89-99

5. Nicolas JL, Robic E, Ansquer D (1989) Bacterial flora associated with trophic chain consisting of microalges, rotifer and turbot larvae: Influence of bacteria on larval survival. Aquaculture 83:237-248

6. Planas M, Cunha I, Munilla R (1994) Utilization de antibióticos para the mejora del culture larval del turbot with fines experimentales. Proc. First Nat. Congress Aquaculture. San Carlés de the Rápita: Ed. Castelló, F \& Calderer, A 765-770

7. Fuller R (1990) Probiotics in agriculture. Agbiotech 2(2):217-220

8. Fuller R (1991) Probiotics in human medicine. Gut 32:439-442 
9. Šolic M, Krstulovic N (1992) Separate and combined effects of solar radiation, temperature, salinity, and pH on the survival of faecal coliforms in seawater. Marine Pollution Bulletin 24, No.8:411-416

10. Auer MT, Niehaus SL (1993) Modeling fecal coliform bacteria-I. Field and laboratory determination of loss kinetics. Water Research 27, No.4:693-701

11. Munro PM, Gauthier MJ, Breittmayer VA, Bongiovanni J (1989) Influence osomoregulation processes on starvation survival of Escherichia coli in seawater. Appl Env Microbiol 2017-2024

12. Lim C-H, Flint KP (1989) The effects of nutrients on the survival of Escherichia coli in lake water. J Appl Bacteriol 66:559-569

13. Chan, AND, Killick EG (1995) The effect of salinity, light and temperature in a disposal environment on the recovery of E. Coli following exposure to ultraviolet radiation. Water Research 29, No.5:1373-1377

14. Cabo ML, Murado MA, González MP, Pastoriza L (1999) A method for bacteriocin quantification. J Appl Microbiol 87:907-914

15. Box GEP, Hunter WG, Hunter JS (1989) In: Estadística Para Investigadores. Barcelona: Ed. Reverté

16. Gompertz B (1825) On the nature of the function expressive of the law human mortality, and on a new mode determining the value of life contingencies. Philos. Trans. R. Soc. London 115:513-585

17. Bigelow WE (1921) The logarithmic nature of thermal death time curves. J Infect Diseases 29, 528

18. Aiba S, Humphrey A., Millis NF (1973) Biochemical Engineering (second edition). New York: Ed. Academic Press

19. Casolari, A (1988) Microbial death. Bazin, M.J., Prosser, J.I. (Eds), Physiological models in microbiology 2. CRC Press, Boca Raton, FL, 1-44

20. Sapru V, Teixeira AA, Smerage GH, Lindsay JA (1993) Comparison of predictive models for bacterial spore population resources to sterilization temperature. J. Food Sci 58(1):223-228

21. Whiting RC (1993) Modeling bacterial survival in unfavorable environments. J Ind Microbiol 12:240-246

22. Daugthry BJ, Davey KW, Munro G, Verbyla AP, (1997) Food processing- a new model for the thermal destruction of contaminating bacteria. In: Jowitt, R. (Ed.), Engineering and Food at ICEF7. Sheffield Academic Press, Sheffield, A113-A116

23. Xiong R, Xie G, Edmondson AE, Sheard MA, (1999) A mathematical model for bacterial inactivation. Int J Food Microbiol 46:45-55 
Table 1: Experimental domain of the orthogonal design and codification of the independent variables.

\begin{tabular}{ccc}
\hline \multirow{2}{*}{$\begin{array}{c}\text { Codified } \\
\text { values }\end{array}$} & \multicolumn{2}{c}{ Natural values } \\
\cline { 2 - 2 } T: Temperature $\left({ }^{\circ} \mathrm{C}\right)$ & S: Salinity $\left(\mathrm{g} . \mathrm{I}^{-1}\right)$ \\
\hline $1 ; 1$ & 30 & 35 \\
-1 & 30 & 18 \\
$-1 ; 1$ & 20 & 35 \\
$-1 ;-1$ & 20 & 18 \\
\hline $0 ; 0$ (4 replicates) & 25 & 26.5 \\
\hline
\end{tabular}

Table 2: Values of $t_{0.5}$ (half life) and $t_{0.1}$ obtained by means the negative exponential and Gompertz models in all the species and conditions assayed.

\begin{tabular}{|c|c|c|c|c|c|c|}
\hline & \multirow[b]{2}{*}{$S\left(g^{-1}\right)$} & \multirow[b]{2}{*}{$\mathrm{T}\left({ }^{\circ} \mathrm{C}\right)$} & \multicolumn{2}{|c|}{$\begin{array}{l}\text { Negative exponential } \\
\begin{array}{c}N=N_{0} \exp (-\mu t) \\
t_{0.5}=\ln (2) / \mu \\
t_{0.1}=\ln (10) / \mu\end{array}\end{array}$} & \multicolumn{2}{|c|}{$\begin{array}{c}\text { Gompertz } \\
\mathrm{N}=\mathrm{a} \exp [-\mathrm{b} \exp (\mathrm{c} t)] \\
t_{0.5}=1 / \mathrm{c}\{\ln [(1+\ln 2) / \mathrm{b}]\} \\
t_{0.1}=1 / \mathrm{c}\{\ln [(1+\ln 10) / \mathrm{b}]\}\end{array}$} \\
\hline & & & $t_{0.5}(\mathrm{~h})$ & $t_{0.1}(\mathrm{~h})$ & $t_{0.5}(\mathrm{~h})$ & $t_{0.1}(\mathrm{~h})$ \\
\hline \multirow[t]{5}{*}{ Lb 2.01} & 18 & 20 & 16.1 & 53.3 & 16.7 & 36.4 \\
\hline & 18 & 30 & 19.9 & 66.2 & & \\
\hline & 35 & 20 & 13.9 & 46.1 & 17.6 & 22.9 \\
\hline & 35 & 30 & 14.0 & 46.5 & & \\
\hline & 26.5 & 25 & 22.7 & 75.5 & & \\
\hline \multirow[t]{5}{*}{ Lb 3.03} & 18 & 20 & 10.8 & 35.9 & & \\
\hline & 18 & 30 & 15.2 & 50.4 & & \\
\hline & 35 & 20 & 16.9 & 56.2 & & \\
\hline & 35 & 30 & 13.9 & 46.2 & & \\
\hline & 26.5 & 25 & 18.9 & 62.9 & & \\
\hline \multirow[t]{5}{*}{ Lb 3.04} & 18 & 20 & 3.4 & 11.3 & & \\
\hline & 18 & 30 & 8.4 & 27.9 & & \\
\hline & 35 & 20 & 2.7 & 8.9 & & \\
\hline & 35 & 30 & 3.3 & 11.0 & & \\
\hline & 26.5 & 25 & 3.8 & 12.5 & & \\
\hline \multirow[t]{5}{*}{ Lc 1.04} & 18 & 20 & & & 21.7 & 43.2 \\
\hline & 18 & 30 & & & 23.5 & 34.8 \\
\hline & 35 & 20 & & & 10.8 & 15.9 \\
\hline & 35 & 30 & & & 16.6 & 23.4 \\
\hline & 26.5 & 25 & 16.6 & 55.2 & 22.6 & 64.2 \\
\hline \multirow[t]{5}{*}{ Pc 1.02} & 18 & 20 & & & 15.4 & 26.8 \\
\hline & 18 & 30 & & & 22.1 & 35.3 \\
\hline & 35 & 20 & & & 12.2 & 14.8 \\
\hline & 35 & 30 & & & 20.5 & 34.6 \\
\hline & 26.5 & 25 & 18.5 & 61.6 & 21.3 & 60.2 \\
\hline
\end{tabular}


Table 3: Parameters fitted to the equation 7

\begin{tabular}{|c|c|c|c|}
\hline & Lb 3.04 & LC 1.04 & Pc 1.02 \\
\hline$b_{0}$ & 4.18 & 17.25 & 18.52 \\
\hline$b_{1}(T)$ & 1.41 & 1.90 & $3.74 \mathrm{~T}$ \\
\hline$b_{2}(S)$ & -1.44 & -4.49 & $-1.19 \mathrm{~S}$ \\
\hline$b_{12}(T S)$ & -1.09 & NS & NOT TS \\
\hline$r^{2}$ & 0.972 & 0.878 & 0.870 \\
\hline$r^{2}$ (corrected for number of variables) & 0.961 & 0.851 & 0.841 \\
\hline
\end{tabular}

Table 4: Results of factorial design for Lb 3.04 and significance analysis for model (7). Y: response (to.5 in hours); $\hat{Y}$ : expected response; NS: non significant coefficient; SS: sum of squares; v: degrees of freedom; MS: mean squares; MSE: mean squares for total error; MSEe: mean squares for experimental error; MSLF: mean squares for lack of fitting; MSM: mean squares for model; MSMLF: mean squares for (model + lack of fitting).

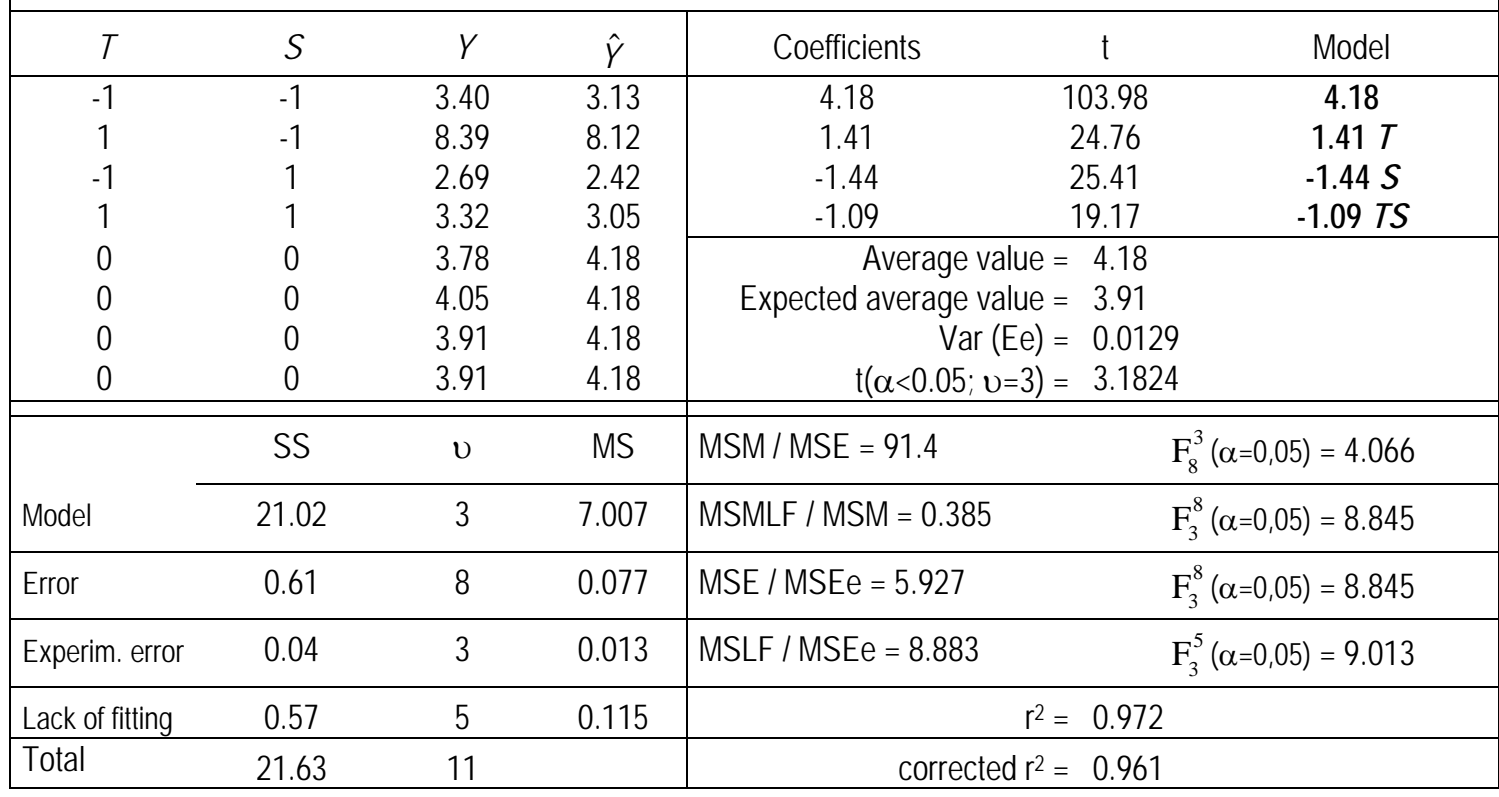




\section{FIGURE CAPTIONS}

Figure 1: Survival of Pediococcus acidilactici (Pc 1.02) under temperature (T) and salinity (S) conditions required by the orthogonal design. Experimental values (points) were adjusted to the negative exponential (solid line) and Gompertz equations (dotted line).

Figure 2: Survival of Lactobacillus casei (Lb 3.04). Conditions and keys as in figure 1.

Figure 3: Response surfaces corresponding to the joint effect of temperature $(T)$ and salinity $(S)$ on the half life $\left(t_{0.5}\right)$ of Lb 3.04, Lc 1.04 and Pc 1.02. Independent variables in codified values. 
FIGURE 1
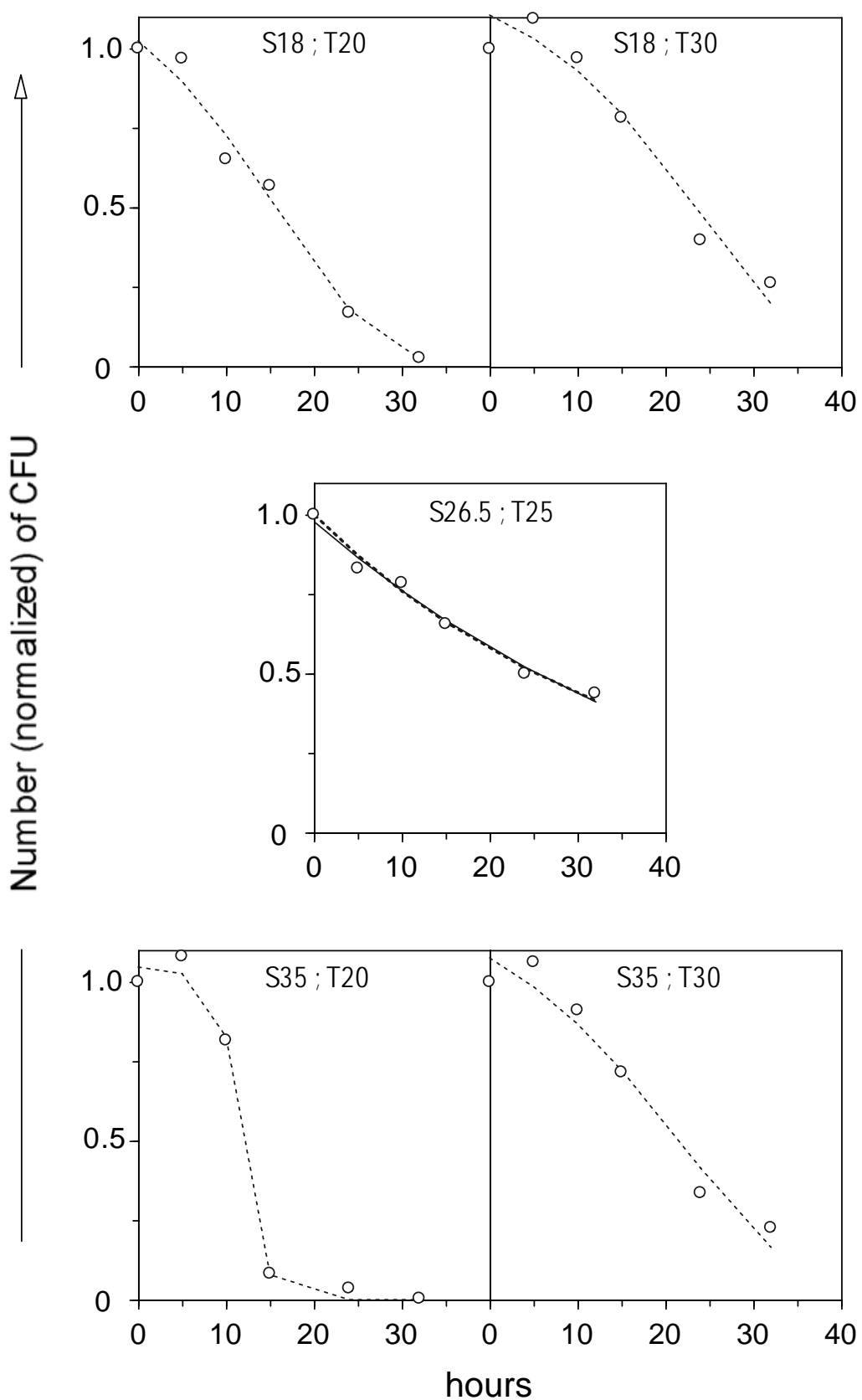
FIGURE 2
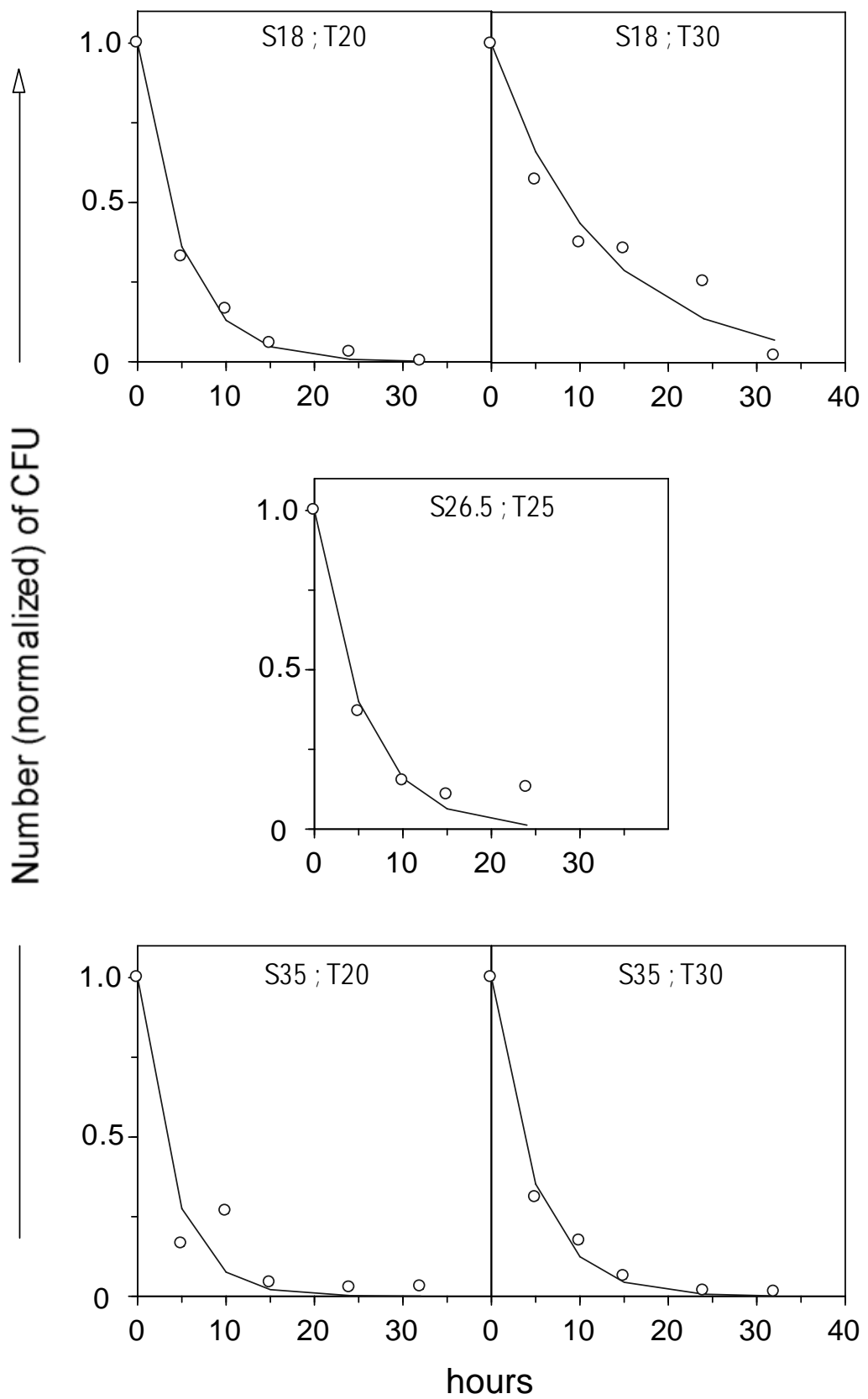
FIGURE 3
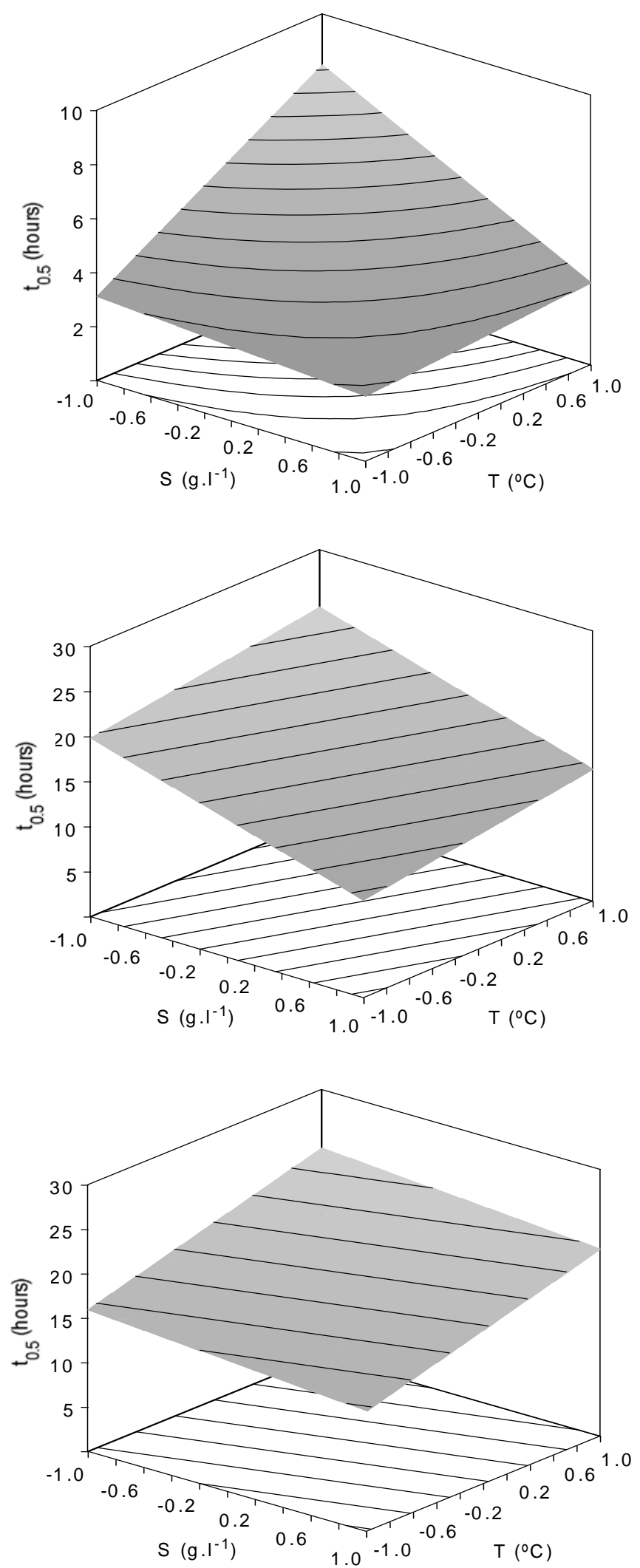